NASA Technical Memorandum 103238

\title{
A Unique High Heat Flux Facility for Testing Hypersonic Engine Components
}

Matthew E. Melis and Herbert J. Gladden

Lewis Research Center

Cleveland, Ohio

Prepared for the

Second International Aerospace Planes Conference

sponsored by the American Institute of Aeronautics and Astronautics in cooperation with the National Aero-Space Plane (NASP) Joint Program Office Orlando, Florida, October 29-31, 1990

\section{NASA}


Matthew E. Melis and Herbert J. Gladden National Aeronautics and Space Administration Lewis Research Center Cleveland, Ohio 44135

\section{Abstract}

A major concern in advancing the state-of-theart technologies for hypersonic vehicles is the development of an aeropropulsion system capable of withstanding the sustained high thermal loads expected during hypersonic flight. Consequently, there is a need for experimental facilities capable of providing a high heat flux environment for testing component concepts and verifying analyses. A hydrogen/oxygen rocket engine was developed at the NASA Lewis Research Center to provide a high enthalpy/high heat flux environment for component evaluation. This "Hot Gas Facility" is capable of providing heat fluxes ranging from $200 \mathrm{Btu} / \mathrm{ft}^{2} / \mathrm{sec}$ on flat surfaces up to $8000 \mathrm{Btu} / \mathrm{ft}^{2} / \mathrm{sec}$ at a leading edge stagnation point. Gas temperatures up to $5500^{\circ} \mathrm{R}$ can be attained as well as Reynolds numbers up to $360000 / f t$. Test articles such as cowl leading edges, transpiration-cooled seals, fuel injectors and cooled panel concepts can be evaluated with gaseous hydrogen as coolant. This facility. its configuration and test capabilities, are discussed in detail. Results from flow characterization experiments are also shown and their implications considered. Future testing by the NASP community planned in the facility is outlined demonstrating the potential contributions to be made by this facility to hypersonic flight research.

\section{Introduction}

With the inception of the National Aerospace Plane program (NASP) in the United States, a significant number of technical challenges have surfaced which are critical to the successful development of NASP as well as other envisioned hypersonic flight vehicles. One major concern in advancing the state-of-the-art technologies for hypersonic vehicles is the development of an aeropropulsion system capable of withstanding the sustained high thermal loads expected during hypersonic flight. Consequently, there is a need for experimental facilities capable of providing a high heat flux environment for testing hypersonic vehicle component concepts and verifying analyses.

The high heat loads encountered by the leading edges of a hypersonic aircraft during flight imposes severe demands on the materials and structures used for these applications. For example, aerodynamic heating at high flight Mach numbers, including the bow-shock/shock interference heating effects on the engine cowl 1 ip, ${ }^{1,2}$ can result in temperature levels which exceed the melting point of most conventional metallic and potential ceramic materials available for aerospace applications today. As a result, an emphasis has been placed on advancing the enabling technology base that will insure the development of unique actively cooled structures capable of withstanding these extreme environmental conditions.
A combined analytical and experimental research effort was initiated at the NASA Lewis Research Center to assess the capability of actively cooled structures to tolerate the high heating rates typical of hypersonic flight. ${ }^{-5}$ The "Hot Gas Facility," a hydrogen/oxygen rocket engine with a 2.3 in. square combustion chamber, provides hot combustion gases up to $5500^{\circ} \mathrm{R}$ and 600 psia to the test articles. A convergent-divergent (C-D) nozzle can be attached to the combustion chamber to achieve supersonic flow of up to Mach 2.5. The test specimens can be mounted in the combustion chamber itself or down stream of the C-D exhaust nozzle to obtain either subsonic or supersonic flow conditions.

A new face plate fuel injector was designed and installed in the facility to provide a uniform temperature profile in the rocket engine combustion chamber. Characterization of the hot gas flow in the test section was performed in order to help define the thermal conditions a test article would experience. Several tests including total temperature measurement of the exhaust gas profile with an aspirated type $\mathrm{R}$ total thermocouple probe, assessment of the heat flux loads with a heat transfer test piece, and flow stream pressure measurements made with a high temperature pressure rake, were used to accomplish this.

Three generic actively cooled cowl leading edge concepts ${ }^{3}$ were developed at NASA Lewis for initial testing in the facility. These concepts are designated as crossflow, parallel flow and impingement flow cooling schemes with either water or gaseous hydrogen as coolant. Several test specimens of each concept were made of different materials and with various amounts of instrumentation. Copper, nickel, and titanium materials were used in order to examine the effects of thermal conductivity on the efficiency of the cooling scheme. The test articles were then evaluated in a wide variety of conditions in the facility.

Upon completion of scheduled in-house testing, the facility was prepared for NASP contractor testing. These tests presently include actively cooled cowl leading edges, as well as actively cooled seals, and retractable fuel injectors. Each of these programs are briefly presented and discussed.

Many lessons have been learned in the development and conduct of this research program. These lessons and the facility operating capabilities are presented in the following along with a discussion of the impact on hypersonic research made by the NASA Lewis effort. 
The Hot Gas Facility can provide Reynolds number, Prandtl number, enthalpy, and heat fluxes similar to those experienced during hypersonic flight. Hydrogen/oxygen combustion gases ranging in temperature from about 2300 to about $5500{ }^{\circ} \mathrm{R}$ at combustion chamber pressures up to $40 \mathrm{~atm}$ are achievable. With modifications to the propellent flow system, pressures up to 60 atm can also be attained. The source of the hot gas mixture is a small rocket engine combustion chamber mounted horizontally with a cross section of 2.3 by 2.3 in. In general, the facility is operated in short bursts of about $3 \mathrm{sec}$. However, tests as long as $30 \mathrm{sec}$ have been made with no damage to the facility hardware.

The test stand and the exhaust scrubber tank inlet pipe are shown during firing in Fig. 1 . Figure 2 is a view (looking from below and upstream) of one of the initial crossflow-cooled test specimens mounted in the exhaust plume.

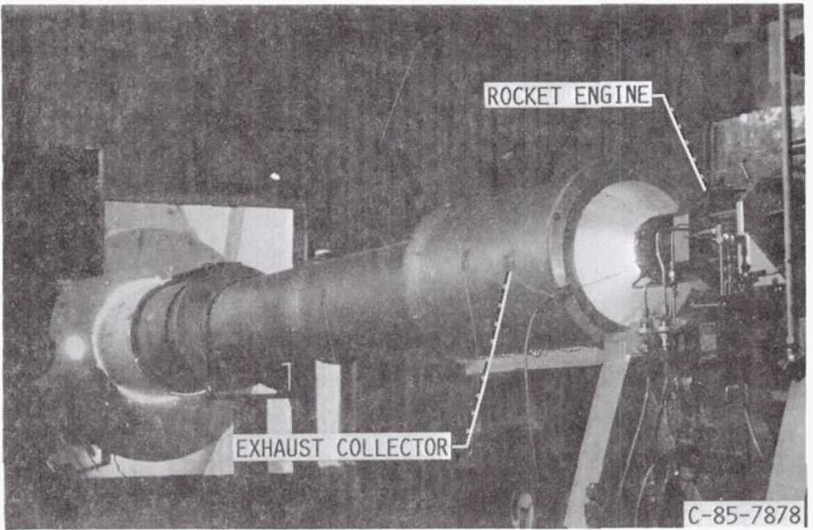

FIGURE 1. - HOT GAS FACILITY DURING FIRING.

Figure 3 shows the major components of the facility such as the fuel and oxidizer injector, the combustion chamber and the test specimen spoolpiece before assembly. To the far left in the figure is the injector. The smaller holes in the center of the face-plate are the 69 oxygen injection sites. Hydrogen is forced through the remainder of the face-plate which is of a platelet construction. The igniter is located in the side wall of the combustion chamber. To date, three variations of injectors have been designed for the facility to provide a uniform hot gas flow and temperature profile from the engine. This topic will be covered in more detail later in the paper.

The component adjacent to the injector is the combustion chamber. The external plumbing shown provides coolant water to channels in the side walls of the component which are constructed of copper in order to enhance the heat transfer to the coolant.

The final assembly to the right is a test specimen spool piece which mounts onto the rear of the combustion chamber. The test specimen is mounted inside the configuration shown such that a throat is formed at the trailing edge of the specimen. This approach provides a subsonic flowfield over

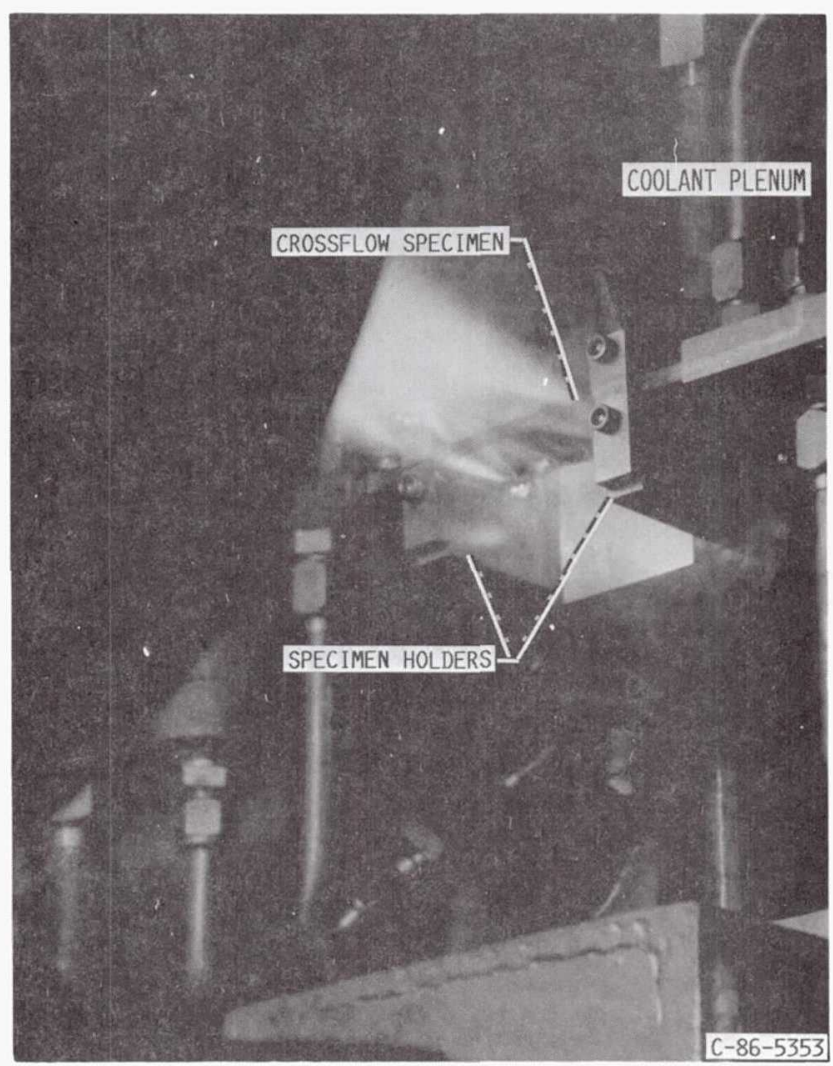

FIGURE 2. - CROSSFLOW TEST SPECIMEN MOUNTED IN EXHAUST PLUME.

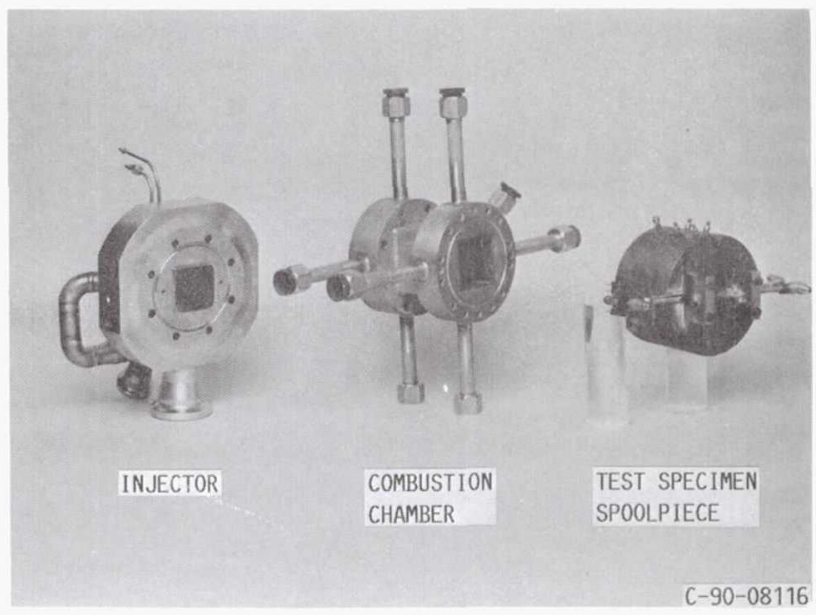

FIGURE 3. - FUEL INJECTOR, COMBUSTION CHAMBER AND TEST SPECIMEN SPOOLPIECE BEFORE ASSEMBLY

the specimen leading edge. However, other types of facility configurations have been utilized for mounting the test specimens.

\section{Facility Configurations}

Two methods in which the facility can be configured for testing are described below. Combustion gases can be discharged to the atmosphere with or without the benefit of a convergentdivergent (C-D) nozzle. Without the nozzle, and with the specimen mounted in a spool piece attached to the combustion chamber (as shown in fig. 3 ), the flow is essentially subsonic even though the absolute velocity of the flow is on the order of $3000 \mathrm{ft} / \mathrm{sec}$. With a C-D nozzle and extension, a supersonic free stream Mach number of 2.5 can be 
achieved at the test specimen. Presently, an expansion attachment is in fabrication for the C-D nozzle to expand the flow to atmospheric pressure. However, a variety of expansion sections can be designed and fabricated to obtain other Mach numbers within the pressure capabilities of the facility. A cross-section sketch of the nozzle and nozzle extension hardware, which are water cooled, are shown in Fig. 4. In addition to mounting a leading edge specimen on the exhaust jet center line, panel or seal specimens can be mounted on the side walls of the test section.

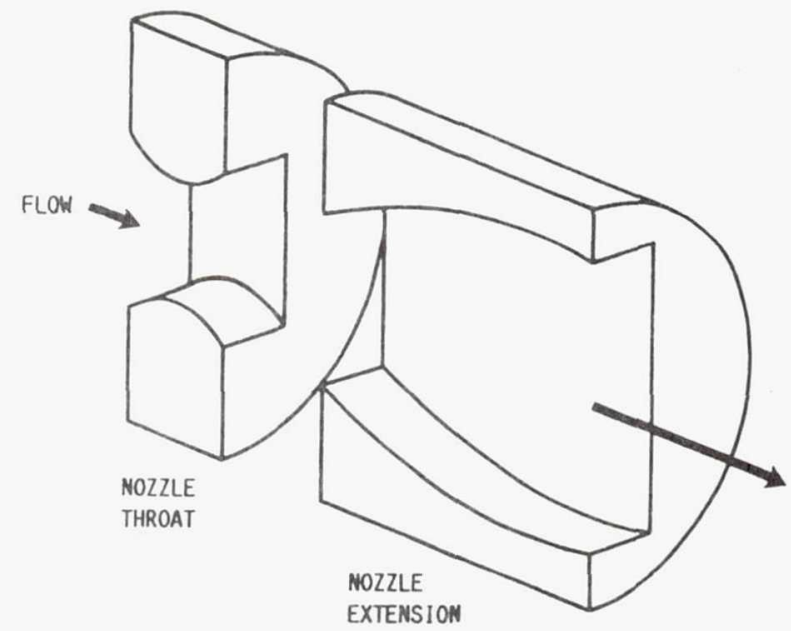

FIGURE 4. - CROSS SECTION OF WATER COOLED C-D NOZZLE AND NOZZLE EXTENSION.

Water and gaseous hydrogen are avallable coolants for test articles in the facility. Water was primarily used in the initial stages of testing due to cost, availability, and safety concerns. once hydrogen was approved for testing in the facility, water was no longer used. In addition, a liquid nitrogen heat exchanger has been built for the facility in order to provide cooled gaseous hydrogen to the test articles if so desired.

\section{Data Acquisition Capabilities}

TRADAR 2.5, a high speed, analog-to-digital recording system is used to record up to 100 data channels at $100 \mathrm{samples} / \mathrm{sec} / \mathrm{per}$ channel of time dependent data. Data from pressure, temperature, flow, and strain sensors can be recorded for subsequent computer processing. A 32-channel recording oscillograph is used to provide immediate data feedback on critical data channels in any given test. Twenty parameters can be recorded in this fashion. The test cell is set up to receive the standard types of data from pressure transducers, thermocouples, and frequency output devices. There are 48 for each of the types $\mathrm{K}, \mathrm{E}$, and $R$ thermocouples. Sixty four channels of signal conditioners as well as 12 frequency-to-voltage converters are available for use with pressure transducers. For photographic documentation, the facility has high-speed motion picture cameras which operate at up to $400 \mathrm{frames} / \mathrm{sec}$ as well as video and $35 \mathrm{~mm}$ remotely operated cameras.

\section{Injector Modifications}

The initial injector used on this program consisted of a 52 element oxygen injector with a rigimesh face plate to control the hydrogen injection. In addition, the igniter was located in the center of the face plate. Temperature profiles from this configuration were very irregular with a pronounced cold spot in the center.

A review of the injector design and the data from the characterization tests of the second injector described in the General Description section demonstrated the need for a new design. It was decided that, in order to improve the propellant mixing, the oxygen would also be injected through a platelet arrangement similar to the hydrogen. This design distributes the fuel and oxidizer more uniformly.

The new design is currently being fabricated at the time of publication. The injector characterization process, discussed in the Facility Calibration section, will be performed on the new injector and is expected to show marked improvements to provide an acceptable test environment. It is assumed that this final design will essentially eliminate any mixing inefficiencies in the test section and will substantially improve the uniformity of the hot gas flow.

\section{Operating Characteristics}

\section{Boundary Conditions}

The facility can provide a high enthalpy gas stream with total temperatures ranging from 2300 to $5500^{\circ} \mathrm{R}$ in the range of 8 to $40 \mathrm{~atm}$. The products of combustion are water vapor and either hydrogen or oxygen depending on whether the test is run fuel rich or oxygen rich. To date, only fuel rich mixtures have been utilized. The Prandtl number for these mixtures is in the range of 0.6 to 0.8 which is comparable to air. In addition, the ratio of specific heats is in the range of 1.2 to 1.5 which is also comparable to that of air. Reynolds number similarities can be maintained up to $360000 / \mathrm{ft}$.

The computed stagnation point heat flux capability ${ }^{5}$ is shown in Fig. 5. The results are shown as a function of the engine combustion chamber pressure at various approach free-stream

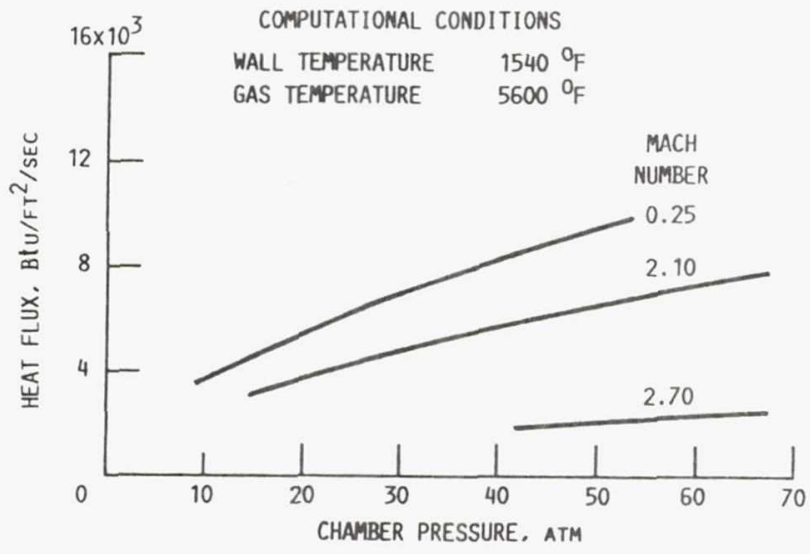

FIGURE 5. - COMPUTED LEADING EDGE STAGNATION HEAT FLUX. 
Mach numbers. These calculations have been verified for subsonic flow conditions. The results demonstrate that, without shock-on-shock phenomena, the Hot Gas Facility can provide peak leading edge heating rates of up to $8000 \mathrm{Btu} / \mathrm{ft}^{2} / \mathrm{sec}$ at subsonic Mach numbers, which is comparable to hypersonic flight conditions. In addition, heat flux on the side wall of the order of 200 to $400 \mathrm{Btu} / \mathrm{ft}^{2} / \mathrm{sec}$ are achievable in a supersonic flowfield.

The heating rates on a typical leading edge model were measured on a heat transfer test specimen fabricated from titanium and instrumented with 22 thermocouples as seen in Fig. 6. The test specimen was subjected to hot gas flow for about 2 sec ranging in oxidizer/fuel ratio (O/F) from 1.17 to 1.7. Data from these tests were reduced using a semi-infinite body assumption and a one-dimensional model of the wall temperature response to a step change in boundary conditions. Typical results are shown in Fig. 7 for the semicylinder portion of the model and show good agreement with the analysis. ${ }^{6}$

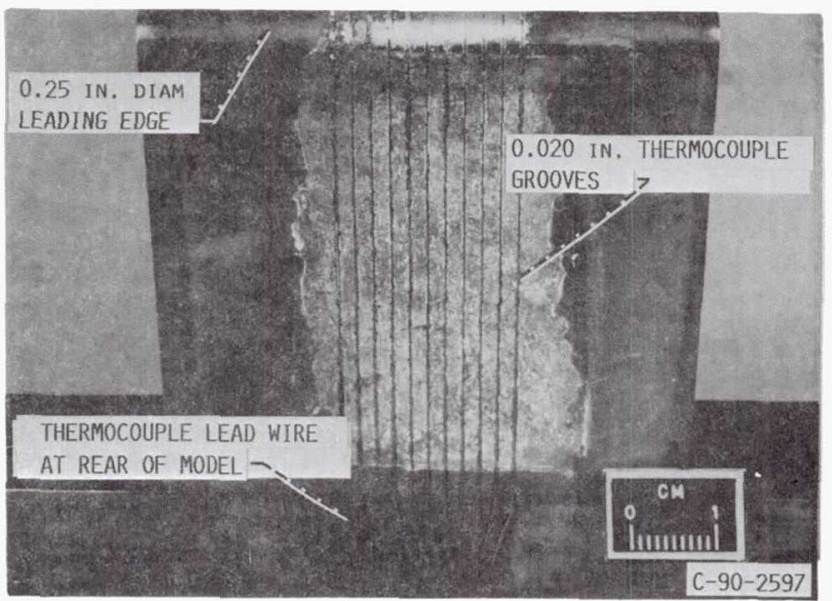

FIGURE 6. - TITANIUM LEADING EDGE HEAT FLUX SPECIMEN.

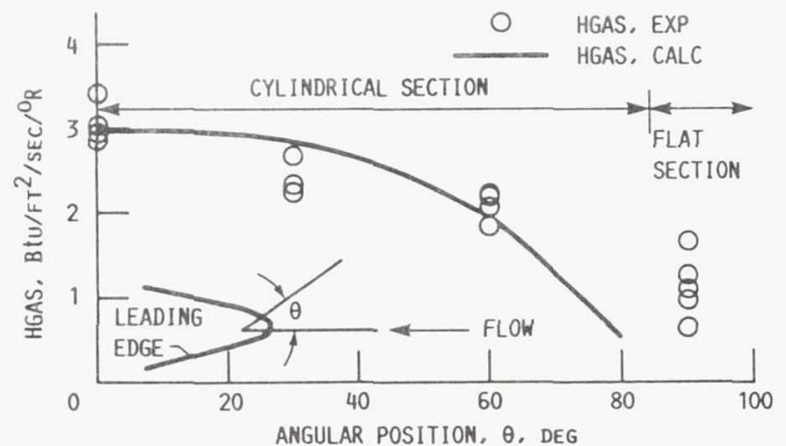

FIGURE 7. - MEASURED LEADING EDGE HEAT TRANSFER COEFFICIENTS.

Thermal paints were also used initially to get a qualitative measure of temperatures across a test article. For the most part, little was learned through their use due to their inability to survive the hostile environment of a test. In addition, the limited temperature latitude for any one paint made it difficult to visualize the severe thermal gradients on a test specimen.

An accurate assessment of the gas temperature profile was made with an aspirated total temperature probe. The probe consisted of a type $R$
(Pt-Rh) thermocouple sheathed in a molybdenum tube to protect it from the combustion gases. The probe was designed such that the hot gasses would enter one end of the tube and stagnate at the thermocouple before being exhausted to the atmosphere. The probe was moved, in steps, across the test section to measure the total temperature of the gases. This type of probe construction is accurate to within about 0.5 percent. Test times were typically on the order of 1 to $2 \mathrm{sec}$ and were performed in the $O / F$ range of 1.0 to 1.5 (gas temperatures from 2300 to $3000^{\circ} \mathrm{R}$ ). Measurements were made on both the horizontal and vertical center lines of the test section. The temperature profiles generally followed a parabolic shape as seen in Fig. 8 (horizontal profile) with minimal data scatter. Even though this type of probe has a relatively slow response time, the test time was sufficient to obtain steady state temperature values.

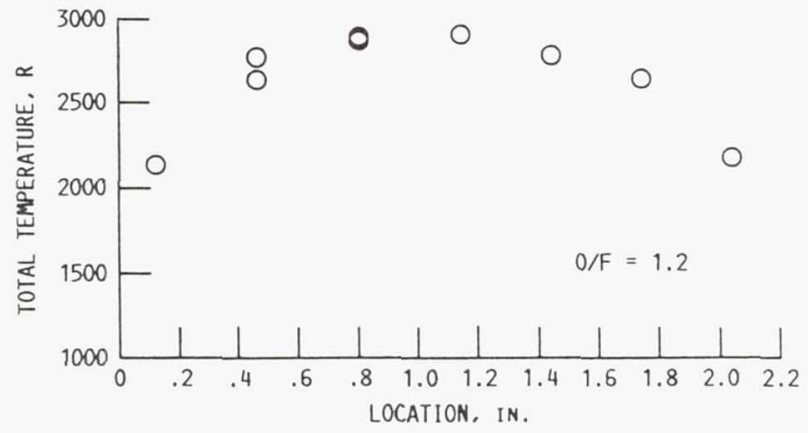

FIGURE 8. - TYPICAL GAS TEMPERATURE PROFILE AT HORIZONTAL CENTER LINE.

Either water or gaseous hydrogen can be used as a coolant for the test specimens. A high pressure system can supply coolant water at a flow rate of $24 \mathrm{gal} / \mathrm{min}$ at pressures up to $82 \mathrm{~atm}$. Hydrogen coolant can be supplied to a test specimen at a maximum flow rate of $0.15 \mathrm{lbm} / \mathrm{sec}$ and a maximum pressure of $70 \mathrm{~atm}$. In addition, the hydrogen can be cooled down to about $150^{\circ} \mathrm{R}$ with the liquid nitrogen heat exchanger discussed earlier. If the $\mathrm{LN}_{2}$ heat exchanger is used during testing, the hydrogen coolant flow and pressure limits are reduced due to the additional pluming.

\section{Facility Calibration}

Calibration and characterization of the hot gas flow in the facility was a major part of this program. The parameters of interest were performance of the fuel injector, temperature uniformity and total temperature profile of the hot gas stream in the test section, the measured heating loads on a test article, and the free stream pressure profile aft of the C-D nozzle.

It was ascertained through inspection of the test articles after initial firings and review of the high speed movies that there was a significant amount of hot streaking in the test section. This was the result of poor distribution or incomplete mixing of the hydrogen and oxygen propellants. Since testing is generally run in a fuel rich mode, theoretically there should be no free oxygen in the combustion gases. Free oxygen in the hot gas stream would represent improper mixing and a higher local $O / F$ ratio forming a hot streak. A method to detect the uniformity of the hot gas flow mixture 
was devised by using columbium bars mounted across the test section in the hot gas flow to determine the hot streak regions. A set of three columbium bars were mounted in the test section and subjected to a short firing. The high melting temperature and low oxidation resistance enabled the columbium bars to withstand the test environment yet readily show regions where significant quantities of oxygen were present. Figure 9 shows a set of bars after testing and the substantial oxidation in several regions.

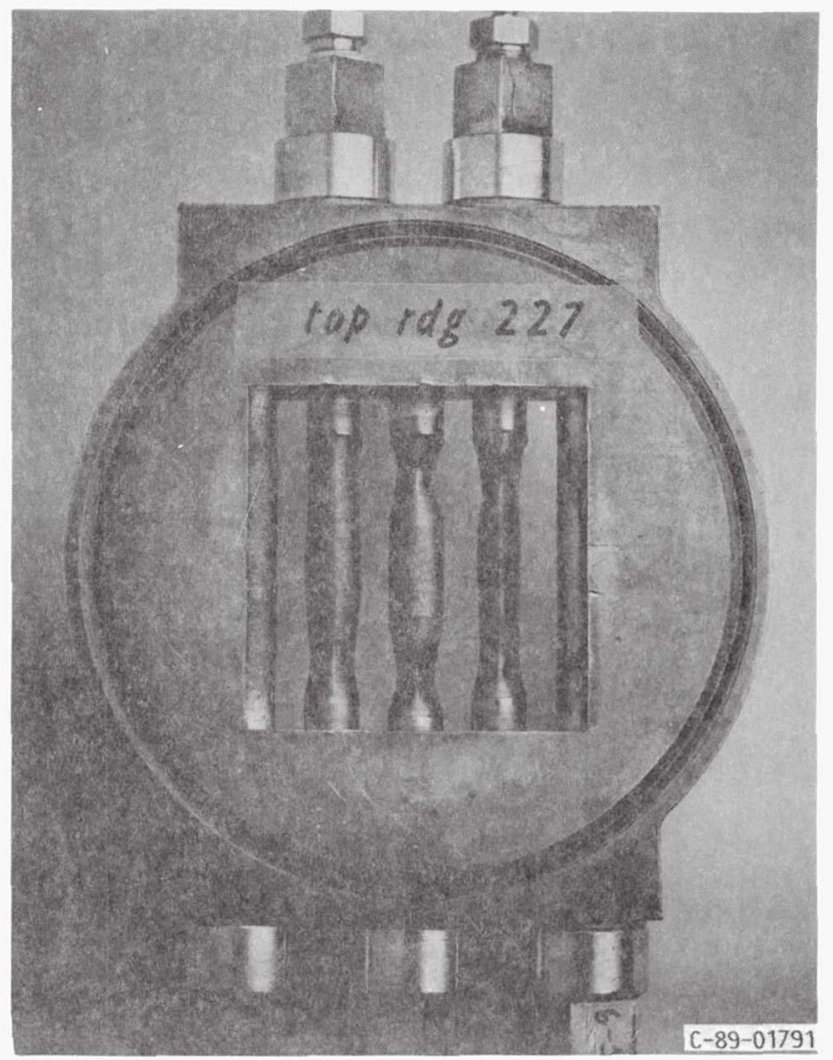

FIGURE 9. - COLUMBIUM BARS AFTER TESTING.

Several sets of bars were tested in both the horizontal and vertical directions. Initial tests showed such poor mixing that steps had to be taken to fine tune the injector. This was done using small stainless steel springs which fit inside the oxygen injector posts. These springs were inserted in posts corresponding with regions of high oxidation on the columbium bars. The springs served to reduce the oxygen flow and to induce some swirl to enhance mixing. The calibration process continued until there was a minimal amount of erosion on the columbium bars.

For supersonic flow testing, an experiment was designed to measure the free-stream pressure profile aft of the contraction to demonstrate the fully expanded flow capability of the C-D nozzle and its extension. A high temperature total pressure rake, shown in Fig. 10, was designed and fabricated from Inconel 600 to make the pressure measurements. As discussed earlier, the nozzle extension was still in fabrication at time of publication. Thus no pressure measurements were made by them.

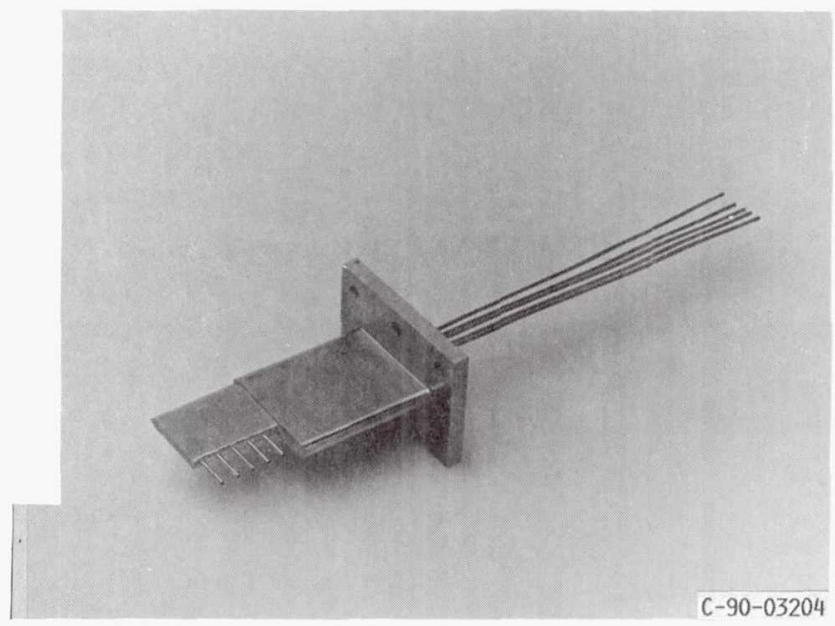

FIGURE 10. - INCONEL HIGH TEMPERATURE PRESSURE RAKE.

\section{Experimental Design Concepts}

\section{In-house concepts}

Three generic cowl leading edge cooling schemes were initially chosen for shakedown testing in the Hot Gas Facility under a cowl lip technology program known by the acronym COLT. These were called the crossflow, parallel flow, and impingement concepts. These concepts are depicted in Fig. 11 showing the cooling path of each. The following paragraphs discuss these concepts only briefly. However, each of these have been discussed in detail in Refs. 4 and 5 .

Initial tests were intended to develop the knowledge base required to test and analyze a wide variety of hardware. The crossflow concept lent itself to early testing because it was easy to fabricate and instrument. Its simple geometry also made it simpler to model on the computer for thermostructural finite element analyses. The crossflow concept was the only one to be tested with both hydrogen and water used as coolants. The others were only tested with hydrogen. A fully instrumented crossflow specimen is shown in Fig. 12 .

The parallel flow cooling scheme was fabricated with both a sharp and blunted leading edge. Its construction was somewhat more complicated than the crossflow configuration in that a face sheet had to be brazed onto a core with the cooling channels milled into it. Knowledge gained from these models helped in developing expertise in brazing and instrumentation, as well as analysis techniques of a more realistic cooling scheme. Figure 13 shows a sharp edged test article after testing. Note the melting started at the leading edge due to the inability of coolant to perform efficiently in that region.

The impingement concept was actually developed many years ago under the auspices of the Hypersonic Research Engine program. ${ }^{7}$ The actual specimen used for testing was fabricated during the HRE program but was not instrumented at the time. Consequently, the only ingtrumentation put on the test specimen were thermocouples attached to the outside surface of the skin. The leading edge and the instrumentation are shown in Fig. 14. Surprisingly, the thermocouples held up quite well under many tests and only two of them were rendered inoperative by the time the testing was completed. 


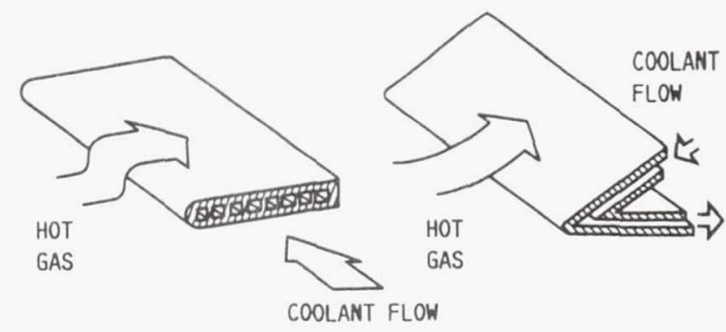

CROSSFLOW

PARALLEL

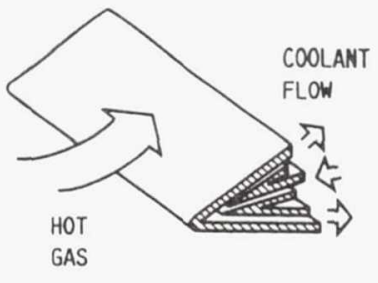

IMPINGMENT

FIGURE 11. - ACTIVELY COOLED COWL LIP CONCEPTS.

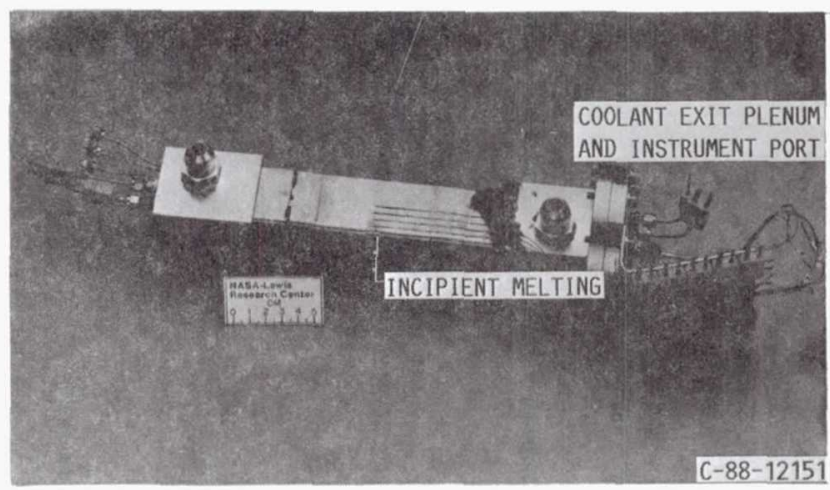

rIGURE 12. - FULLY INSIRUMENIAL NICKEL CROSSFLOW SPECIMEN.

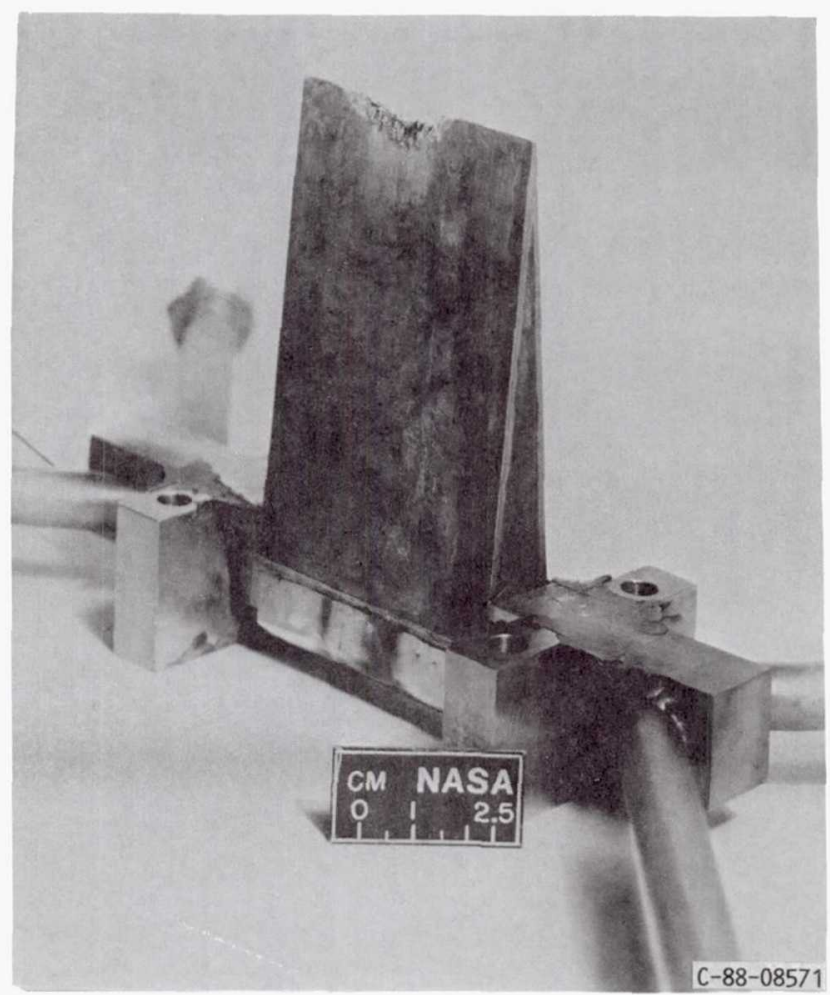

FIgURE 13. - COPPER PARALLEL FLOW TEST SPECIMEN.

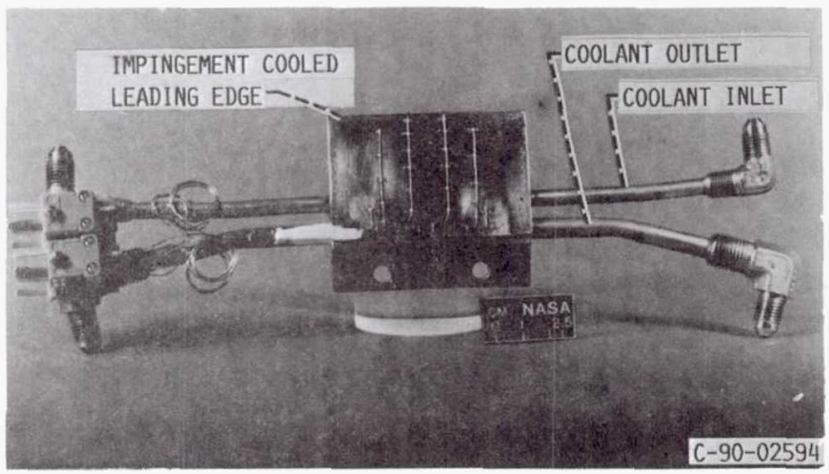

FIGURE 14. - NICKEL IMPINGEMENT COOLED TEST SPECIMEN. 


\section{NASP Contractor Concepts}

There are presently four actively cooled test concepts planned for testing by NASP contractors in the hot gas facility. Two of these are inlet leading edge concepts. One is a liquid metal heat pipe concept with a hydrogen heat sink. The primary purpose is to demonstrate the operation of a prototype liquid metal heat pipe with heat gink in a realistic heat flux environment. The other is a convection cooled leading edge which also uses high pressure gaseous hydrogen as coolant. These concepts will be tested in a subsonic flow-field to attain a high level of stagnation point heat flux.

In addition, two other actively-cooled structures will be tested which demonstrate the versatility of the facility. A hydrogen transpiration cooled geal concept will be evaluated in a supersonic flow environment. The seal experiment will demonstrate the feasibility of using a porous ceramic material in this kind of application. A retractable fuel injector concept will also be evaluated in supersonic flow environment at realistic heat flux levels.

\section{Discusgion and Conclusions}

The Hot Gas Facility and its capabilitieg have been summarized herein. Although its test envelope does not include the shock-on-shock interference heat flux levels that might be desired, the facility does provide heat flux levels up to $8000 \mathrm{Btu} / \mathrm{ft}^{2} / \mathrm{sec}$ at a leading edge stagnation point. In addition, side wall heat flux levels of the order of 200 to $400 \mathrm{Btu} / \mathrm{ft}^{2} / \mathrm{sec}$ are achievable in a supersonic flowfield. Its usefulness to the NASP community has been demonstrated through extensive calibration of the flowfield and testing of hydrogen cooled structures over a range of temperatures and pressures. Reynolds number, Prandt 1 number, enthalpy, and heat flux similar to those expected during hypersonic flight can be achieved. In addition, there is a significant amount of analytical correlation of the experimental results. This unique facility has proven itgelf to be a simple, reliable, and cost effective means for evaluation of engine components of hypersonic vehicles.

\section{References}

1. Holden, M.S., Moselle, J.R., Wieting, A.R. and Glass, C., "Studies of Aerothermal Loads Gener ated in Regions of Shock/Shock Interaction In Hypersonic Flow," AIAA Paper 88-0477, Jan 1988.

2. Glass, C.E., Wieting, A.R., and Holden, M.S., "Effect of Leading Edge Sweep on Shock-Shock Interference at Mach 8," AIAA Paper 89-0271, Jan 1989 .

3. Melis, M.E., Gladden, H.J., Schubert, J.F., Westfall, L.J., and Trimarchi, P.A., "A Unique Interdisciplinary Research Effort To Support Cowl Lip Technology Development for Hypersonic Applications," NASA TP-2876, 1989.

4. Gladden, H.J. and Melis, M.E., "A High Heat Flux Experiment for Verification of Thermostructural Analysis," NASA TM-100931, 1988.

5. Gladden, H.J., Melis, M.E., Mockler, T.T., and Tong, M., "Thermal/structural Analyses of Several Hydrogen-Cooled Leading-Edge Concepts for Hypersonic Flight Vehicles," AIAA Paper 90-0053, Jan 1990 .

6. Jukauskas, A. and Ziugzda, J., Heat Transfer of a Cylinder in Crosgflow Hemisphere Publishing corp. 1985 .

7. Killackey, J.J., Katinszky, E.A., Tepper, S., Vuigner, A.A., Wright, C.C., and stockwell, G.G., "Thermal-Analysis Design Study of an Airframe-Integrated Scramjet. Final Report," NASA CR-159039, 1980. 


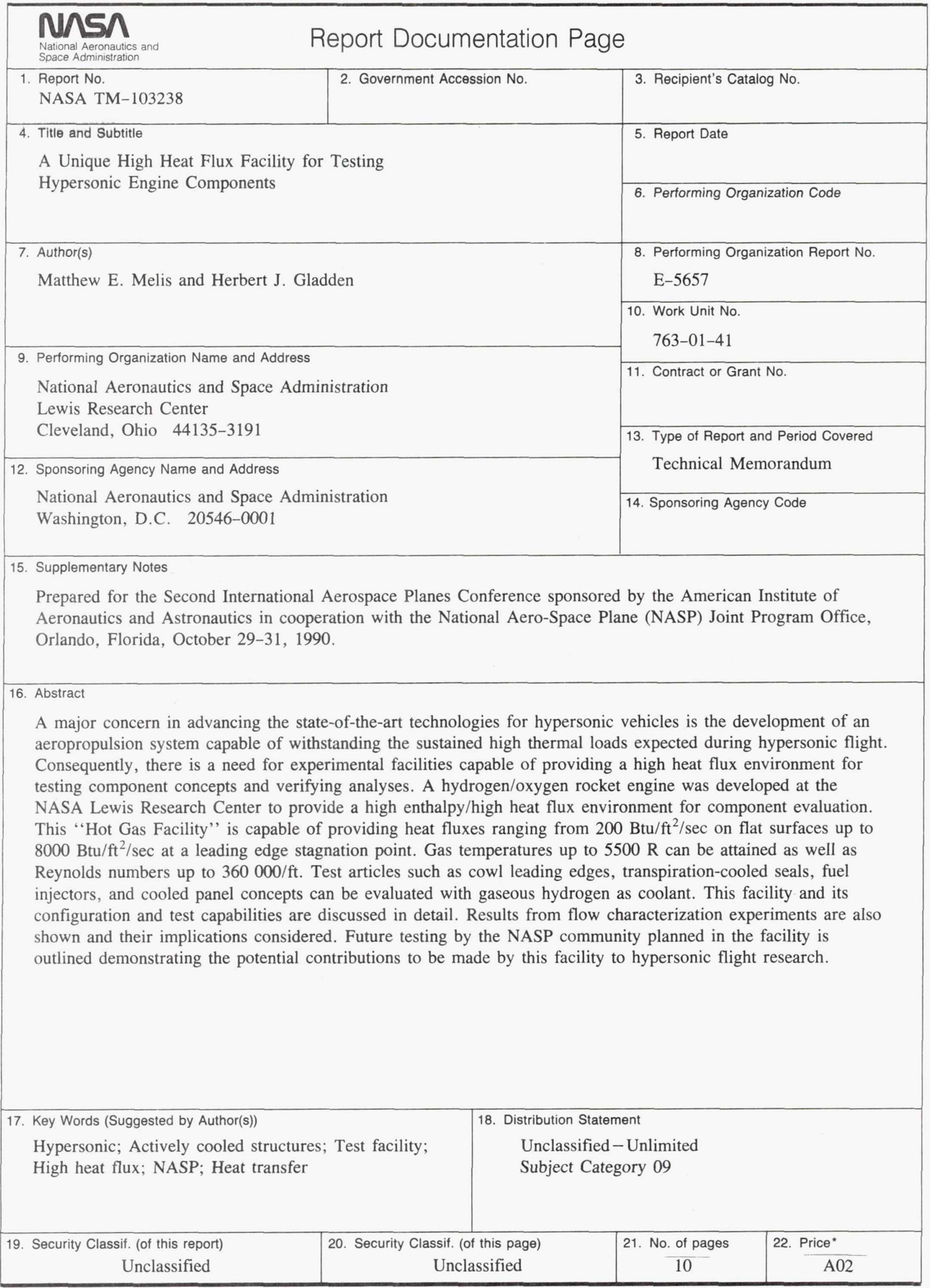

